\title{
Paper Dual-band Bisected Psi Antenna for 3G, Wi-Fi, WLAN and Wi-MAX Applications
}

\author{
Penchala Reddy Sura ${ }^{1}$ and S. Narayana Reddy ${ }^{2}$ \\ ${ }^{1}$ Faculty of Visvodaya Engineering College, Kavali, India \\ ${ }^{2}$ Sri Venkateswara University, Tirupati, India
}

https://doi.org/10.26636/jtit.2020.135519

\begin{abstract}
This paper presents an inexpensive and simple dual-band bisected psi antenna for 3G, Wi-Fi, WLAN, and WiMAX applications is presented. The antenna comprises a bisected psi-shaped patch on a low-price FR4 substrate with a cropped ground plane on the other side, and is fed by a $50 \Omega$ microstrip line. It operates at two distinct frequency bands of 1.87-2.76 GHz and 5.16-5.75 $\mathrm{GHz}$ with $\left|S_{11}\right| \leq-10 \mathrm{~dB}$.
\end{abstract}

Keywords-3G, bisected psi, dual-band, stub, WLAN.

\section{Introduction}

The challenges faced while designing multi-band antennas are as follows: achieving broad bandwidth along with adequate gain and a stable radiation pattern [1]-[3].

The principles of monopole antenna design techniques are employed for the design and analysis of dual-band antennas. A monopole antenna basically comprises a radiating strip positioned on a partial ground plane. In these techniques, conducting stubs of various lengths are utilized to achieve dual-band operation. Various types of monoor multi-layered structures are utilized to obtain the wide bandwidth with appropriate gain. The inherent drawback is that the antenna becomes heavy and bulky. The gains obtained in these methods are limited to maximum 0.5 to $0.8 \mathrm{~dB}$ at resonant frequencies [4]-[9].

Antennas compliant with (1.92-1.98 GHz and 2.11$2.17 \mathrm{GHz}), 4 \mathrm{G}(2.3-2.4 \mathrm{GHz}), \mathrm{Wi}-\mathrm{Fi}(2.4-2.485 \mathrm{GHz}$ and 5.15-5.85 GHz) WLAN (2.4-2.48 GHz, 5.15-5.35 GHz and 5.725-5.825 GHz) and WiMAX $(2.5-2.69 \mathrm{GHz}$, 3.4-3.69 GHz, 5.25-5.85 GHz) systems play a very important role in numerous commercial applications. A large number of dual-band antennas has been designed and investigated up to date. These antennas are designed with planar dipoles used as their radiating elements [10]-[16]. In this paper, an inexpensive and simple bisected psi antenna for $3 \mathrm{G}$, Wi-Fi, WLAN, and WiMAX communication is designed and investigated. The projected antenna utilizes microstrip stubs to make the fabrication easy and simple to provide connectivity with other elements.

The proposed design is then optimized by using HFSS software to achieve better results.

\section{The Antenna Design}

The proposed bisected psi antenna acts as a monopole aerial, as a major portion of the ground plane is removed. The length of the stub should be $\frac{\lambda_{g}}{4}$ at its resonance frequency.

The guide wave length is:

$$
\lambda_{g}=\frac{\lambda_{0}}{\varepsilon_{r e f f}},
$$

where the effective dielectric constant is:

$$
\varepsilon_{r e f f}=\frac{\varepsilon_{r}+1}{2}+\frac{\varepsilon_{r}-1}{2}\left[1+12 \frac{h}{W_{p}}\right]^{-\frac{1}{2}} \text { for } \frac{W_{p}}{h} .
$$

The final optimized lengths are slightly different from the values calculated with the use of the $\lambda_{g}$ expression, due to the fringing effect of stubs.

The width of the radiating stub is given by:

$$
\begin{gathered}
\frac{w}{h}=\frac{8 \mathrm{e}^{a}}{\mathrm{e}^{2 a-2}} \text { for } \frac{w}{h}<2, \\
\frac{w}{h}=\frac{2}{\pi}\left[b-1-\ln (2 b-1)+\frac{\varepsilon_{r-1}}{2 \varepsilon_{r}}\left\{\ln (b-1)+0.39-\frac{0.69}{\varepsilon_{r}}\right\}\right] \\
\text { for } \frac{w}{h}>2,
\end{gathered}
$$

where

$$
\begin{gathered}
a=\frac{Z_{q}}{60} \sqrt{\frac{\varepsilon_{r}+1}{2}}+\frac{\varepsilon_{r}-1}{\varepsilon_{r}+1}\left(0.23+\frac{0.11}{\varepsilon_{r}}\right), \\
b=\frac{377 \pi}{2 Z_{0 \sqrt{\varepsilon_{r}}}} .
\end{gathered}
$$


Table 1

Parameters of presented aerial design

\begin{tabular}{|c|c|}
\hline Parameters & Size $[\mathrm{mm}]$ \\
\hline$W$ & 38 \\
\hline$L$ & 41 \\
\hline$s$ & 24.5 \\
\hline$r$ & 33 \\
\hline$l 1$ & 22.6 \\
\hline$d$ & 4.1 \\
\hline$t$ & 12 \\
\hline$l 2$ & 6.4 \\
\hline$h$ & 1.6 \\
\hline
\end{tabular}

The antenna contains a bisected psi-shaped patch on one side of a $1.6 \mathrm{~mm}$ thick FR4 substrate, which has a cropped ground plane on the other side. The substrate has the $\varepsilon_{r}=4.4$ and loss tangent of 0.02 . A $50 \Omega$ microstrip line with the dimensions $l 1 \times d$ is utilized to feed

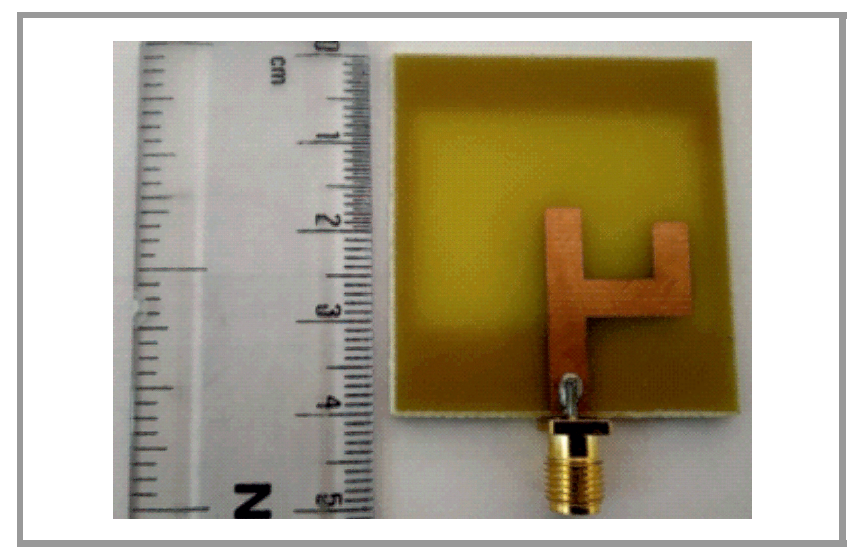

Fig. 1. Front view of the fabricated antenna.

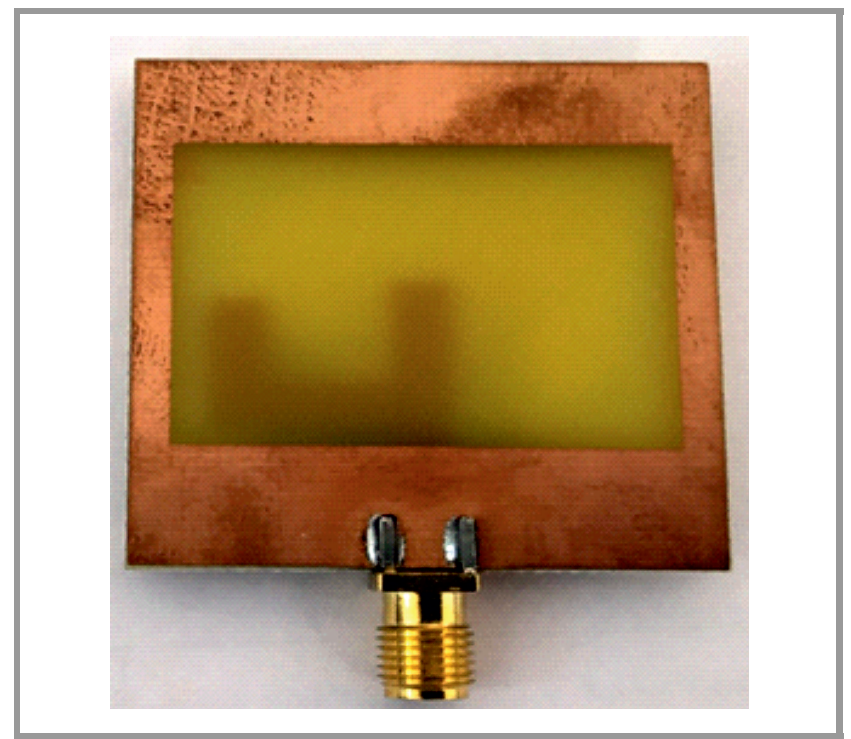

Fig. 2. Rear view of the fabricated antenna.

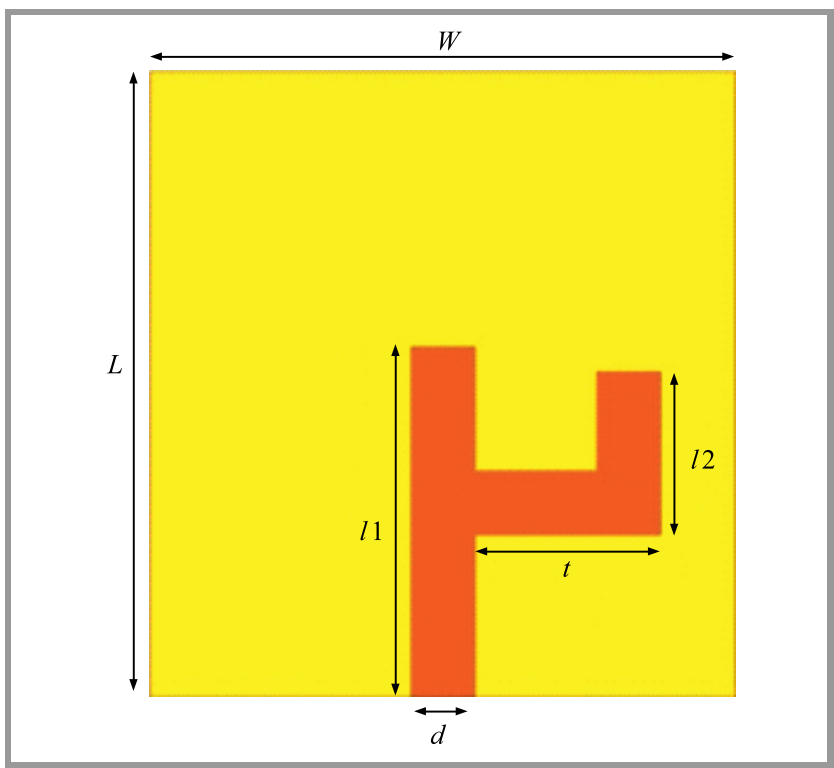

Fig. 3. Front aspect.

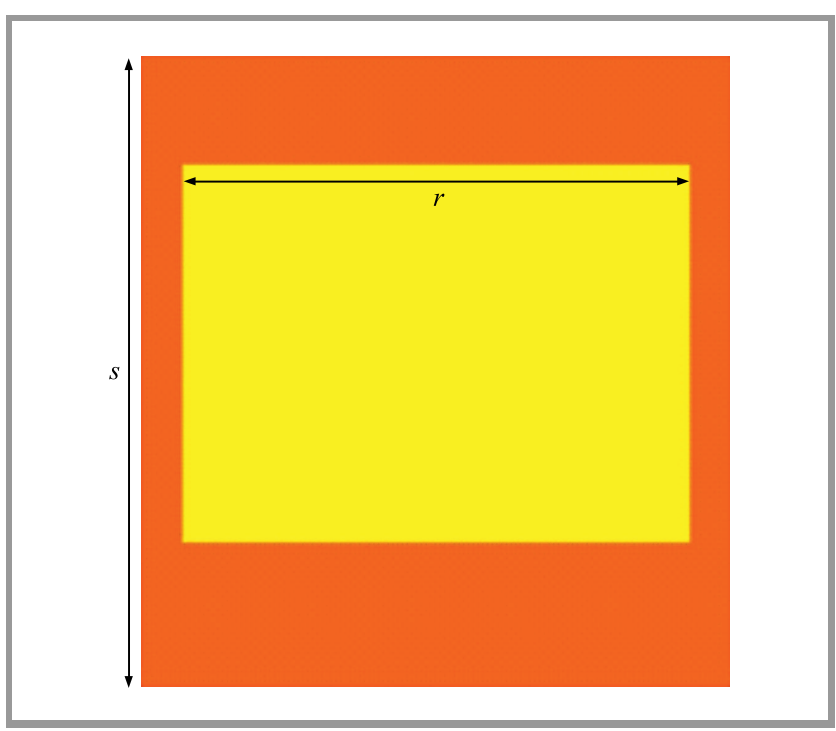

Fig. 4. Rear aspect.

the signal. The total size is $L \times W$. The ground plane is truncated with a rectangular slot with the size of $s \times r$. Impedance matching is mainly affected by the dimensions and location of the rectangular slot in the ground plane. The bandwidth of two bands of the antenna is also affected by the dimensions and location of the rectangular slot. The bisected psi antenna contains two radiating stubs to provide radiation within the two bands. The length of the radiating stub must be equal to $\frac{\lambda_{g}}{4}$ at its resonance frequency. The diagonal length of the rectangular ground plane slot should be $\frac{\lambda_{g}}{4}$.

The dimensions were optimized by performing parametric analysis with the help of FEM-based Ansoft HFSS software (Table 1). Next, the antenna was fabricated to examine the its performance over the specific operating bands (Figs. 1-4). 


\section{Antenna Improvement}

Next, the antenna was improved in three steps using HFSS (Fig. 5). The "Ant 1" design contains only one central radiating strip $(22.6 \times 4.1 \mathrm{~mm})$ on a substrate with complete ground. Ant 1 resonates only at $3.455 \mathrm{GHz}$ and has $S_{11} \leq-10.26 \mathrm{~dB}$. It exhibits a higher return loss because of improper impedance matching. The $S_{11}$ plot of the Ant 1 is shown in Fig. 4.

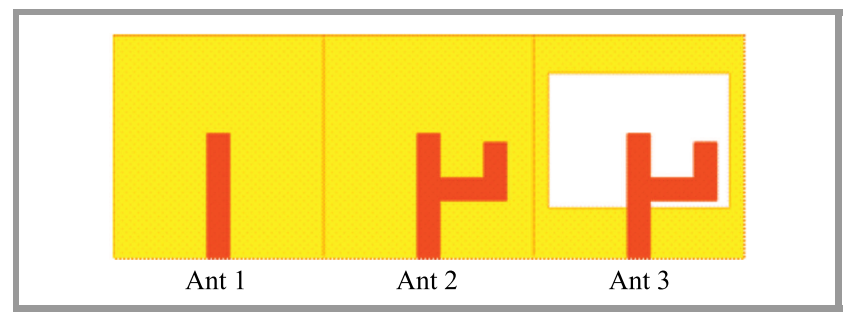

Fig. 5. Modifications of the bisected psi antenna.

Ant 2 is a modification of Ant 1 developed by adding a folded conducting strip $(6.1 \times 4.1 \mathrm{~mm})$ to the main strip of Ant 1, on the left-hand side. Now, Ant 2 operates at two frequencies of $2.98 \mathrm{GHz}$ and $5.78 \mathrm{GHz}$, with unsatisfactory $S_{11}$ values due to an impedance mismatch.

In the third step, the ground plane of Ant 2 was truncated with a rectangular slot (size $s \times r$ ) to obtain the Ant 3 version.

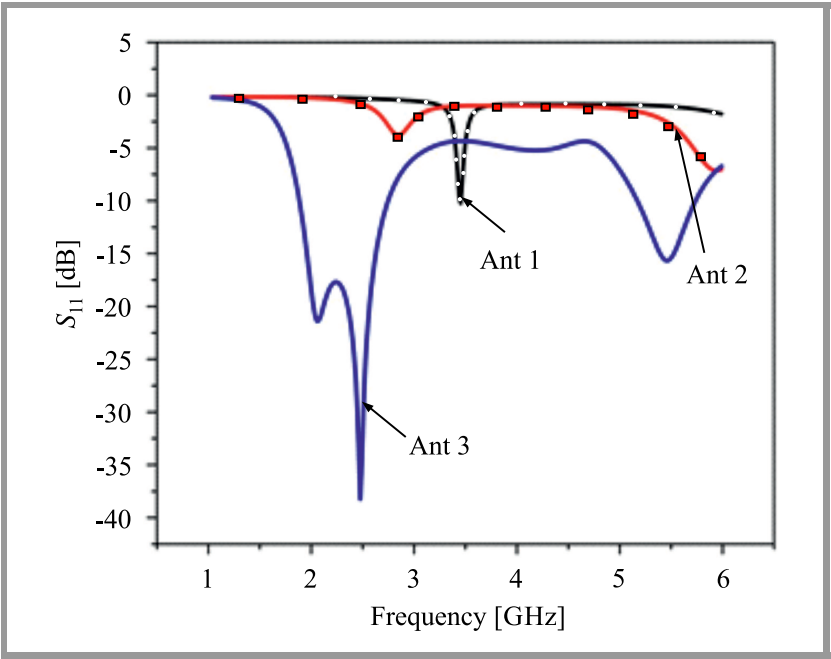

Fig. 6. $S_{11}$ coefficient versus operating frequency. (For color pictures visit www.nit.eu/publications/journal-jtit)

This slot improves the quality of impedance matching and reduces reflection losses. Now, Ant 3 operates at two bands $(1.788-2.765 \mathrm{GHz}$ and $5.1-5.74 \mathrm{GHz})$ with $S_{11}$ below $-10 \mathrm{~dB}$ (Fig. 6).

\section{Results}

A simulation of the proposed dual band bisected psi antenna (Ant 3) has been performed by using HFSS software.
The design was also prototyped to investigate its functionality over the desired operating bands. A network analyzer was used to measure S11 (return loss). Acceptable values of return loss are below $-10 \mathrm{~dB}$. The $S_{11}$ values measured for this specific antenna are compared with simulation results Fig. 7.

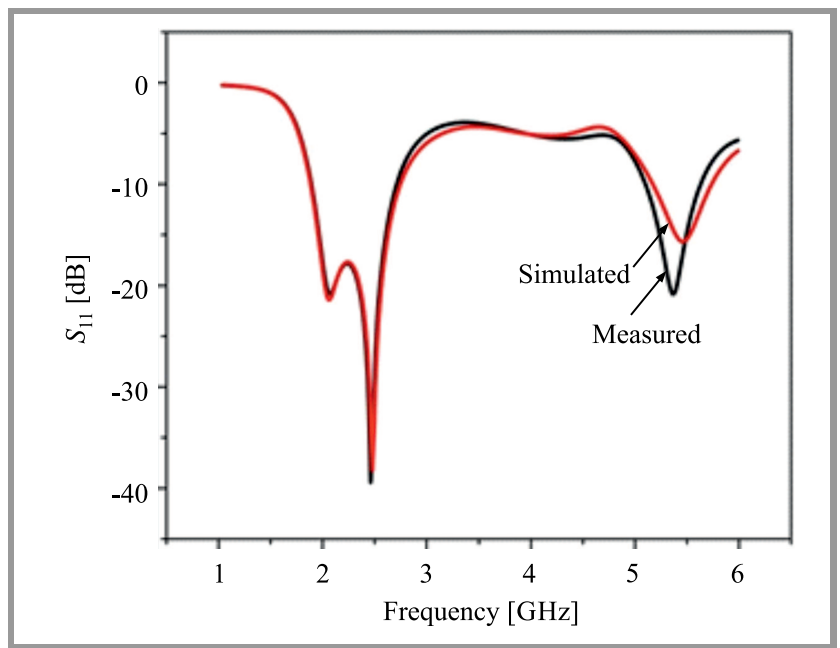

Fig. 7. Return loss $S_{11}$ over frequency.

The figure clearly shows that the proposed antenna covers the $1.87-2.76 \mathrm{GHz}$ and $5.16-5.75 \mathrm{GHz}$ frequency bands due to impedance matching enhancement offered by the truncated ground plane. The simulated $S_{11}$ values closely match the actual measurement results.

Differences between the simulated and measured S11 values are caused by flaws in fabrication, losses in substrate, environment surrounding the measurement equipment and imperfections in the coaxial cable port and connector.

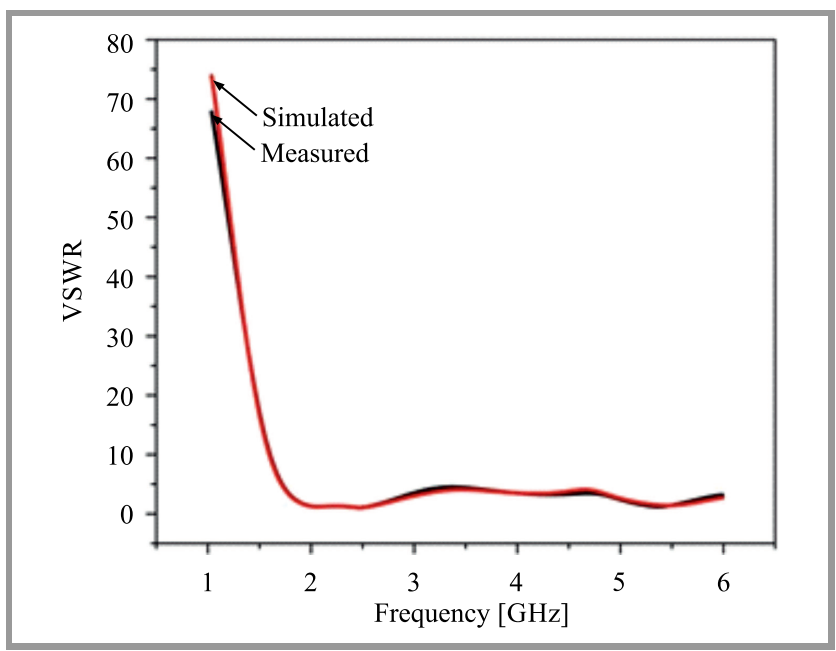

Fig. 8. VSWR over frequency for the bisected psi antenna.

Simulated VSWR values of the bisected psi antenna precisely match the measured plot (Fig. 8). Within the resonant bands, VSWR varies from 1 to 2 . 
Current distribution $J_{s}$ on the surface of the bisected psi antenna at 2.4 and $5.2 \mathrm{GHz}$ is presented in Figs. 9-10,

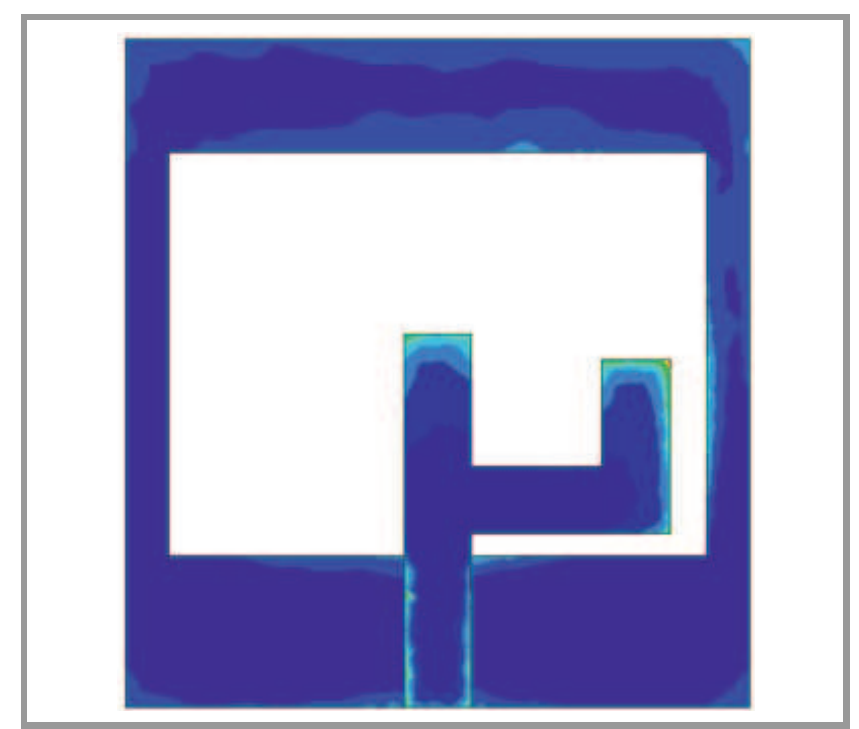

Fig. 9. Current distribution at $2.4 \mathrm{GHz}$.

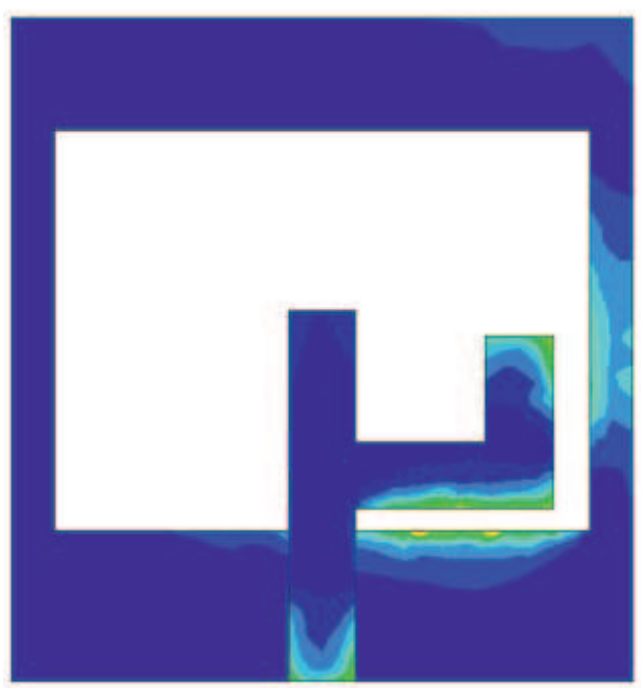

Fig. 10. Current distribution at $5.2 \mathrm{GHz}$.

Table 2

Comparison with other designs

\begin{tabular}{|c|c|c|c|}
\hline Reference & $\begin{array}{c}\text { Bandwidth } \\
{[\mathrm{GHz}]}\end{array}$ & $\begin{array}{c}\text { Gain } \\
{[\mathrm{dB}]}\end{array}$ & $\begin{array}{c}\text { Application } \\
\text { usability }\end{array}$ \\
\hline$[16]$ & 1.23 & 0.6 & Wi-Fi, WiMAX, 5G \\
\hline$[17]$ & 0.55 & 6.2 & GPS, Wi-Fi \\
\hline$[18]$ & 1.4 & 3.7 & WLAN, WiMAX \\
\hline$[20]$ & 0.14 & 6.2 & Wi-Fi, ISM \\
\hline$[21]$ & 0.8 & 2 & $\begin{array}{c}\text { Bluetooth, } \\
\text { WLAN, WiMAX }\end{array}$ \\
\hline Proposed & 1.44 & 4.6 & $\begin{array}{c}\text { 3G, 4G, Wi-Fi, } \\
\text { Bluetooth, } \\
\text { WLAN, WiMAX }\end{array}$ \\
\hline
\end{tabular}

respectively. The radiation visible at $2.4 \mathrm{GHz}$ is mainly caused by the center conducting stub. Similarly, radiation at $5.2 \mathrm{GHz}$ is mainly caused by the folded conducting strip.

A comparison of performance of the bisected psi antenna with existing antenna designs is presented in Table 2. The bisected psi antenna offers broad bandwidth, moderate gain and is useful in a higher number of applications when compared to other aerials.

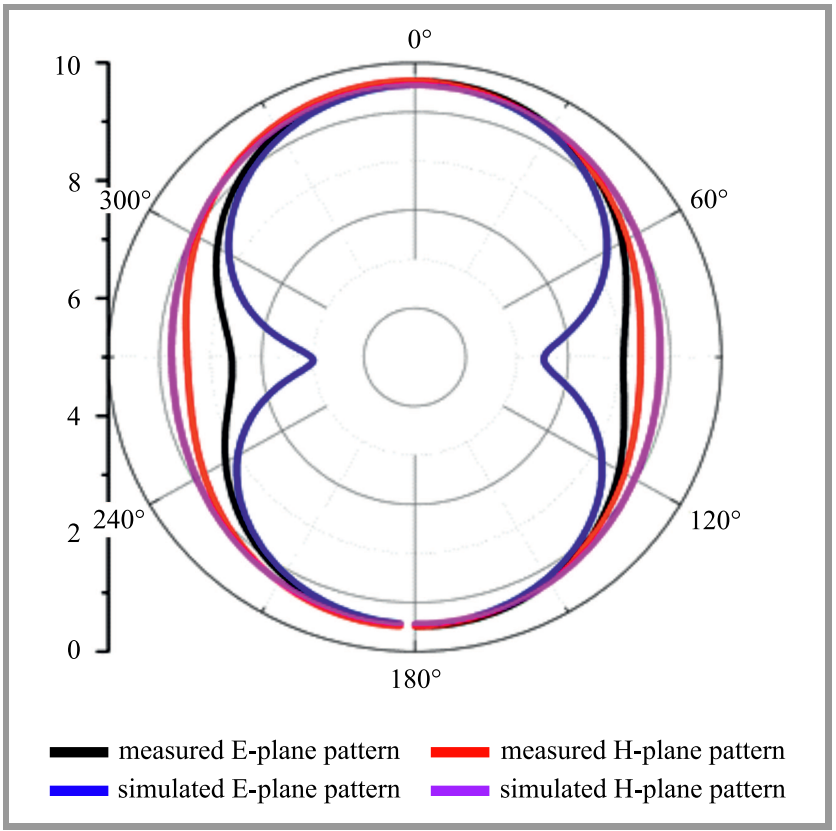

Fig. 11. Antenna radiation pattern at $2.4 \mathrm{GHz}$.

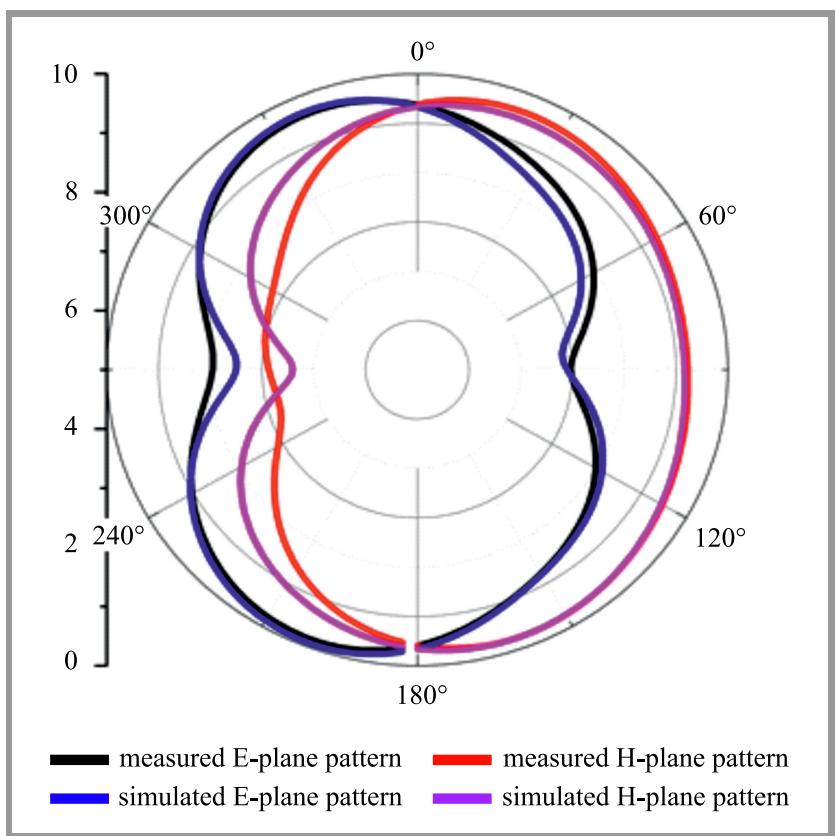

Fig. 12. Antenna radiation pattern at $5.2 \mathrm{GHz}$.

Radiation patterns of the bisected psi antenna have been measured in an anechoic chamber. The principal E- and 
H-plane patterns of the antenna were simulated and measured separately for two operating frequencies of 2.4 and $5.2 \mathrm{GHz}$. The radiation patterns are illustrated in Figs. 11-12. The gain of the proposed antenna at 2.4 and $5.2 \mathrm{GHz}$ is 2.7 and $4.6 \mathrm{~dB}$, respectively. From the figures, it is clear that the designed antenna exhibits an omnidirectional radiation pattern in the $\mathrm{H}$-plane and a monopole like-pattern in the E-plane, due to truncated ground and $\frac{\lambda_{g}}{4}$-long radiating stubs. The antenna offers a higher gain at the two distinct resonating bands, with an acceptable reflection loss. Therefore, it may be considered as a better aerial for 3G, Wi-Fi, WLAN and WiMAX applications. From Figs. 11-12, it is also clear that the measured radiation patterns closely match the simulated results. The bisected antenna exhibits maximum radiation values in the broadside direction. The H-plane pattern is obtained when $\phi=0^{\circ}$, and the E-plane pattern is obtained when $\phi=90^{\circ}$, which means that the radiation patterns are stable over both bands.

\section{Conclusions}

An inexpensive dual band bisected psi antenna has been presented. The reversed conducting L-shaped stub is connected to the center radiating stub to obtain double band functionality. It has been proved that the antenna built on an inexpensive F4 laminate is capable of operating at resonant bands of 1.87 to $2.76 \mathrm{GHz}$ and 5.16 to $5.75 \mathrm{GHz}$, with an acceptable return loss level. The simulated results closely match to actual, measured values. The proposed antenna may be utilized in MIMO and array antenna applications.

\section{Acknowledgments}

The authors wish to thank the VTA society for their support and encouragement in the design and fabrication of the bisected psi antenna. We also thank KL University for support in conducting the measurements.

\section{References}

[1] C. A. Balanis, Antenna theory: Analysis and Design, 4th ed. Hoboken, NJ: Wiley, 2016 (ISBN: 978-1-118-64206-1).

[2] R. Garg, P. Bhartia, I. Bahl, and A. Ittipiboon, Microstrip Antenna Design Handbook. Boston: Artech House, 2001 (ISBN: 978-0890065136).

[3] Y.-L. Kuo and K.-L. Wong, "Printed double-T monopole antenna for 2.4/5.2 GHz dual-band WLAN operations", IEEE Trans. on Antenn. and Propag., vol. 51, no. 9, pp. 2187-2192, 2003 (doi: 10.1109/TAP.2003.816391).

[4] H.-D. Chen, J.-S. Chen, and Y.-T. Cheng, "Modified inverted-L monopole antenna for $2.4 / 5 \mathrm{GHz}$ dual-band operations", Electron. Lett., vol. 39, no. 22, pp. 1567-1568, 2003 (doi: 10.1049/el:20031037).

[5] S. Chaimool and K. L. Chung, "CPW-fed mirrored-L monopole antenna with distinct triple bands for WiFi and WiMAX applications", Electron. Lett., vol. 45, no. 18, pp. 928-929, 2009 (doi: 10.1049/el.2009.1390).
[6] D. Parkash, R. Khanna, V. Kumar, and A. B. Chaudhary, "Novel dual-band CPW-fed monopole slot antenna for WLAN/WiMAX applications", Int. J. of Comp. Sci. and Technol., vol. 1, no. 1, pp. 21-24, 2010 [Online]. Available:

https://pdfs.semanticscholar.org/ af9f/d5423664c96b201b63b206e1220bd19b4e98.pdf

[7] X.-F. Li, "Design of a CPW-fed wideband planar monopole antenna with omni-directional pattern improvement", in Proc. IEEE Int. Conf. on Commun. Prob.-Solv. ICCP 2015, Guilin, China, 2015, pp. 271-273 (doi: 10.1109/ICCPS.2015.7454148).

[8] R. Rahman, K. M. Morshed, S. Sabrin, and M. Rahman, "Wideband planar monopole antenna for LTE, GSM, Bluetooth, WiMAX, DCS, PCS, and GPS mobile terminals", in Proc. 2nd Int. Conf. on Elec. Inform. and Commun. Technol. EICT 2015, Khulna, Bangladesh, 2015, pp. 309-313 (doi: 10.1109/EICT.2015.7391967).

[9] L. Pazin and Y. Leviatan, "Inverted-F laptop antenna with enhanced bandwidth for Wi-Fi/WiMAX applications", IEEE Trans. on Antenn. and Propag., vol. 59, no. 3, pp. 1065-1068, 2011 (doi: 10.1109/TAP.2010.2103036).

[10] J. Li, "An omnidirectional microstrip antenna for WiMAX applications", IEEE Anten. and Wirel. Propag. Lett., vol. 10, pp. 167-169, 2011 (doi: 10.1109/LAWP.2011.2118730).

[11] X. Sun, G. Zeng, H. Yang, and Y. Li, "A compact quadband CPWfed slot antenna for M-WiMAX/WLAN applications", IEEE Antenn. and Wirel. Propag. Lett., vol. 11, pp. 395-398, 2012 (doi: 10.1109/LAWP.2012.2192901).

[12] R. J. Chitra, B. R. Karthik, and V. Nagarajan, "Design of double L-slot microstrip patch antenna for WiMAX and WLAN application", in Proc. Int. Conf. on Comput., Commun. and Appl., Dindigul, Tamilnadu, India, 2012, pp. 1-4 (doi: 10.1109/ICCCA.2012.6179223).

[13] K. Yu, Y. Li, and Y. Wang, "Multi-band metamaterial-based microstrip antenna for WLAN and WiMAX applications", in Proc. Int. Applied Comput. Electromag. Soc. Symp. ACES 2017, Florence, Italy, 2017, pp. 1-2 (doi: 10.23919/ROPACES.2017.7916032).

[14] Y.-C. Luan et al., "Compact triple-band monopole antenna with a wide-slot ground for WLAN/WiMAX applications", in Proc. Int. Worksh. on Microw. and Millim. Wave Circ. and Syst. Technol., Chengdu, China, 2013, pp. 127-130 (doi: 10.1109/MMWCST.2013.6814585).

[15] I. Chen and C. Peng, "Printed broadband monopole antenna for WLAN/WiMAX applications", IEEE Antenn. and Wirel. Propag. Lett., vol. 8, pp. 472-474, 2009 (doi: 10.1109/LAWP.2009.2020310).

[16] X. Fang, G. Wen, D. Inserra, Y. Huang, and J. Li, "Compact wideband CPW-fed meandered-slot antenna with slotted Y-shaped central element for Wi-Fi, WiMAX, and 5G applications", IEEE Trans. on Antenn. and Propag., vol. 66, no. 12, pp. 7395-7399, 2018 (doi: 10.1109/TAP.2018.2869254).

[17] J. Chen, K. Tong, A. Al-Armaghany, and J. Wang, "A dual-band dual-polarization slot patch antenna for GPS and Wi-Fi applications", IEEE Antenn. and Wirel. Propag. Lett., vol. 15, pp. 406-409, 2016 (doi: 10.1109/LAWP.2015.2448536).

[18] L. Li, X. Zhang, X. Yin, and L. Zhou, "A compact triple-band printed monopole antenna for WLAN/WiMAX applications", IEEE Antenn. and Wirel. Propag. Lett., vol. 15, pp. 1853-1855, 2016 (doi: 10.1109/LAWP.2016.2539358).

[19] M. van Rooyen, J. W. Odendaal, and J. Joubert, "High-gain directional antenna for WLAN and WiMAX applications", IEEE Antenn. and Wirel. Propag. Lett., vol. 16, pp. 286-289, 2017 (doi: 10.1109/LAWP.2016.2573594).

[20] D. Chaturvedi, A. Kumar, and S. Raghavan, "A nested SIW cavitybacking antenna for Wi-Fi/ISM band applications", IEEE Trans. on Antenn. and Propag., vol. 67, no. 4, pp. 2775-2780, 2019 (doi: 10.1109/TAP.2019.2896670).

[21] P. S. Bakariya, S. Dwari, M. Sarkar, and M. K. Mandal, "Proximitycoupled microstrip antenna for Bluetooth, WiMAX, and WLAN applications", IEEE Antenn. and Wirel. Propag. Lett., vol. 14, pp. 755-758, 2015 (doi: 10.1109/LAWP.2014.2379611). 


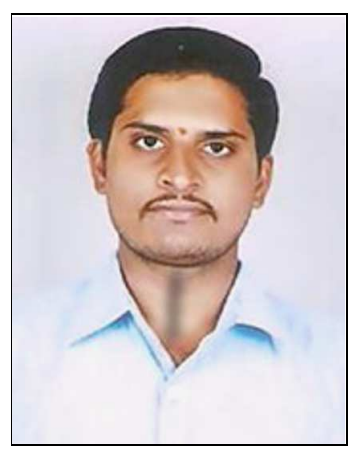

Penchala Reddy Sura is working as an Assistant Professor at the Electronics and Communication Engineering Department, Visvodayad Engineering College (VEC), Kavali, India. He has received the Bachelor's degree in Electronics and Communication from the JNTUH, Hyderabad, in 2008 and Master's degree in Digital Electronics from JNTUK, Kakinada, in 2010. He has published ten papers in various international journals. His areas of interest include RF and antenna design.

E-mail: sura.440@gmail.com

Visvodaya Engineering College

Kavali, India

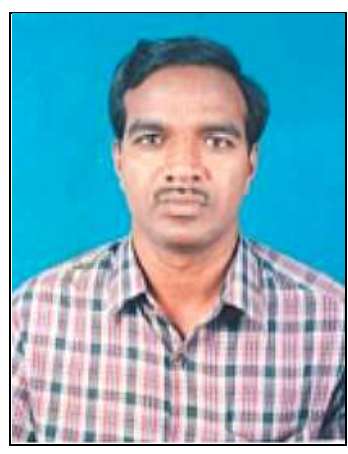

S. Narayana Reddy is working as Professor at the Electronics and Communications Engineering Department, Sri Venkateswara University (SVU), Tirupati, India. He received his Master's degree in Microwave and Radar Engineering from IITK in 1988, and Ph.D. from the SVU, Tirupati in 1999. He has published numerous papers in various national and international journals. His areas of interest include RF, antenna design and signal processing.

E-mail: snreddysvu@yahoo.com

Sri Venkateswara University

Tirupati, India 